\title{
European prescribers' attitudes and beliefs on biologicals prescribing and automatic substitution
}

\author{
Madelaine Feldman, MD, FACR; Michael S Reilly, Esq
}

\begin{abstract}
Introduction: The European Union (EU) and the European Medicines Agency (EMA) have led the development of a regulatory framework for biosimilars since 2004. By end of December 2019, 64 biosimilars of 15 originator biological medicines have a marketing authorization in Europe. Now, for the second time, the Alliance for Safe Biologic Medicines (ASBM) asked European prescribers for their views on the prescribing, adverse drug reaction reporting, automatic substitution and switching of biologicals and biosimilars.

Methods: In March 2019, the ASBM surveyed 579 prescribers in France, Germany, Italy, Spain, Switzerland and the UK. Prescribers were asked for their views on authority over prescribing and dispensing of biologicals/biosimilars, reporting biological/biosimilar use and adverse drug reactions (ADR) and switching. There were also questions related to their familiarity with, knowledge of, attitudes to, and beliefs in, biosimilars.

Results: Since the previous European prescriber study conducted in 2013, the percentage of respondents considering themselves highly familiar with biosimilar medicines has increased from $76 \%$ to $90 \%$. Four out of five prescribers said they are legally required to report ADR that are brought to their attention and they file detailed ADR reports taking 10-20 minutes. Four out of five prescribers feel very strongly about having control over what is prescribed and dispensed to their patients. While highly comfortable prescribing biosimilars to naïve patients, physician comfort level decreased when switching a stable patient to a biosimilar. Comfort level decreased further when prescribers were asked about switching a patient to a biosimilar for non-medical reasons, e.g. cost, and further still if the switch is initiated by a third party.

Conclusion: European physicians have increased their familiarity with biosimilars since the 2013 survey. Physicians increasingly believe they should always have control of treatment decisions including the decision to switch to a biosimilar. It was also highlighted that governments should make multiple therapeutic options available through tenders.
\end{abstract}

Keywords: biological medicines, biosimilar, EU, prescribers, substitution, survey

\section{Introduction}

Healthcare systems across the globe face resource and budget constraints. Biosimilar drug products offer less expensive alternatives to brand-name originator drug products and can thus offer some relief to healthcare costs. Biosimilars are highly similar and have no clinical meaningful differences; but are not identical to originator biologicals. As countries seek to control health costs and expand access to biological therapies, building physician confidence in biosimilars is critical to promoting their use and reaping the cost benefits.

The European Union (EU) and the European Medicines Agency (EMA) have led the development of a regulatory framework for biosimilars. In 2005, EMA established the first biosimilars approval pathway that was distinct from generics approval [1]. Since then, EMA has developed and refined a comprehensive set of regulatory guidelines on which biosimilar applications are reviewed and approved or rejected. By the end of 2019, 58 biosimilars of 15 originator biological medicines have a marketing authorization in Europe [2]. The European biosimilars market is currently the largest in the world, representing approximately $60 \%$ of the global biosimilar market and growing consistently year on year [3].

At present, once authorized, EMA applies a 'same-label' (generic) approach to biosimilar product labels [4]. However, there are concerns over whether this is sufficient to ensure appropriate drug switching and product traceability. There is ongoing debate about what information is appropriate in the naming and labelling of biosimilars. In the US, FDA released its requirements for the non-proprietary naming of biological products in January 2017 [4]. Prior to this, the Alliance for Safe Biologic Medicines (ASBM) carried out surveys of Australia and EU prescribers and US pharmacist perspectives on the naming of these products. Overall, both groups believed that naming should make biosimilars distinguishable from originator products [5-7]. The ASBM is an organization composed of diverse healthcare groups including patients, physicians and medical innovators. It is funded by its many member partners that are made up of international organizations and companies [8].

The interchangeability of biosimilars is viewed differently in countries across the world. This is particularly marked by the approaches to interchangeability and substitution in the US and Europe [9]. 'In the US, insurance mandates can result in formulary changes requiring patients to be switched from a reference product to a biosimilar strictly for cost reasons'. In Europe, automatic substitution of originator biologicals with biosimilars is rare as this practice excludes physicians from decisions regarding the treatment of patients. There have been a number of surveys and workshops carried out across the world (Australia [5], Europe [4, 6], South America [10] and the US [11]) that have asked for prescriber opinions on prescribing practices, naming and labelling of biologicals. In terms of naming, prescribers in Australia, Europe and the US, overall, agreed that there is a need for distinguishable non-proprietary names to be given to all medications. In South America, knowledge about biosimilars 
varied in different countries surveyed (Argentina, Brazil, Colombia and Mexico) and revealed gaps in understanding and in the use of distinguishable names for biologicals.

In 2019, the ASBM commissioned 15-minute web-based surveys to be carried out by biological prescribers in six Western European countries (France, Germany, Italy, Spain, Switzerland and the UK) to document their perspectives on biological substitution. This survey mirrors their previous European prescriber survey conducted in 2013 [6] (both survey reports can be found at www.safebiologics.org/surveys).

Overall, the 2019 survey showed that awareness of biosimilars in the countries had increased since the 2013 survey. Specifically, more physicians (90\%) rated themselves as being 'Familiar' or 'Very familiar' with biosimilars than did in 2013 (76\%). A strong majority of respondents (82\%) felt that it is either 'Very important' or 'Critical' for them to decide which biological medicine is dispensed to their patients, representing a $10 \%$ increase over the results of the 2013 survey. Again, a strong majority of respondents (84\%) considered authority to prevent a substitution either 'Very important' or 'Critical', another 10\% increase over the 2013 findings. In 2019, physicians remained uncomfortable with switching a stable patient to a biosimilar for nonmedical reasons. Since the 2013 survey, there has also been a sharp increase in physicians who are highly uncomfortable with a non-medical substitution performed by a third party.

It is hoped that the findings of this study may serve as a resource for other countries in developing biosimilar policies that can build physician confidence in biosimilars. Confidence that will increase biosimilar uptake and reduce government expenditures on biological products.

\section{Sample characteristics and methodology}

In March 2019, 579 prescribers practising in six specified European countries (France, Germany, Italy, Spain, Switzerland and the UK) completed the 15-minute web-based survey that was administered in the respondents' native language - French, German, Italian, Spanish, or English. The survey was commissioned by the ASBM and was a refreshed version of that carried out in 2013 [6]. The questionnaires were developed as a collaboration among ASBM management, ASBM membership and Industry Standard Research (ISR) management. No 'validation' was conducted as the instruments did not measure higher level 'constructs'. They are purely direct measures of opinion and attitude.

Potential respondents were identified in - and recruited from - a large, global, commercial database/panel of healthcare professionals. The response rate was high because people in this database/panel have already indicated a willingness to participate in market research. In addition, their specialties were known prior to recruitment, which decreased the rate of disqualification, as if someone was identified as representing a specialty that did not qualify for the study, they were not invited.

Respondents were paid a stipend for their participation. Stipends ranged from US $\$ 37.00$ to US $\$ 48.00$, depending on the specialty.

\section{Prescriber eligibility criteria}

1. Must prescribe biological medicines in their practice

2. Must practice in France, Germany, Italy, Spain, Switzerland, or UK

3. Must specialize in one of 10 practice areas: Dermatology, Endocrinology, Gastroenterology, Haematology-Oncology, Immunology, Nephrology, Neurology, Oncology, Ophthalmology, Rheumatology

4. Must have been in practice for one year or more

\section{Online survey}

The surveys were administered by ISR. In summary, prescribers were asked to rate:

1. The importance of retaining sole authority to decide the most suitable biological for their patients.

2. The importance of retaining the authority to deny/prevent a substitution by indicating "Do Not Substitute" or similar language when prescribing.

3. Their comfort level with: a) prescribing a biosimilar to a new (treatment-naïve) patient; and b) switching a stable patient from an originator biological to a biosimilar.

4. Their comfort level with a biosimilar switch for non-medical reasons, e.g. cost, coverage, a) when performed by the physician; and b) when performed by a third party.

5. The importance of awarding government tenders on originator biologicals and biosimilars to multiple suppliers.

6. The importance of national tender offers including factors besides price.

ISR provided statistical significance tests by country and practice area for most questions. The information from these tests made it possible to determine which answers were most significant amongst prescribers from different countries and working in different practice areas.

\section{Information on survey participants}

Participants were sourced from six countries and across 10 therapeutic areas. The detailed breakdown of this information is as follows. Table 1 provides details of the survey sample disposition.

A total of 579 responses were received:

- France: $97(17 \%)$

- Germany: 97 (17\%)

- Italy: $97(17 \%)$

- Spain: 96 (17\%)

- Switzerland: 95 (17\%)

- United Kingdom: 97 (17\%)

\section{Table 1: Complete survey sample disposition}

\begin{tabular}{|l|r|}
\hline \# invited & 3,979 \\
\hline \# did not respond & 3,007 \\
\hline \# responded & 972 \\
\hline \# screened out for lack of qualification & 103 \\
\hline \# started and did not complete & 290 \\
\hline \# completed responses & 579 \\
\hline
\end{tabular}


The breakdown of the practitioner's primary therapeutic areas is as follows:

Neurology (14\%), Rheumatology (14\%), Gastroenterology (13\%), Ophthalmology (12\%), Nephrology (12\%), Endocrinology (11\%), Dermatology (10\%), Oncology (6\%), Immunology (5\%) and Haematology-Oncology (3\%).

The largest group of prescribers (47\%) practice in a hospital setting, with the remainder in academic medical centres (23\%), private/family practice (18\%), multi-specialty clinics (8\%), community settings (3\%), and other settings (1\%).

Respondents' mean experience level was 15.5 years in practice. Forty per cent of responders had been practising medicine for 11-20 years, $24 \%$ for more than 21 years, $23 \%$ for $6-10$ years, and $13 \%$ for $1-5$ years.

Seventy-nine per cent of responders said they commonly treat patients who are using biological medicines prescribed by another healthcare provider.

Respondents use different sources to learn about the details of a medicine for prescribing and monitoring, see Figure 1.

All data refer only to those who completed the survey. All data were analysed in MS Excel and checked manually.

\section{Results}

\section{Familiarity with biosimilars}

\section{Familiarity with biologicals versus biosimilars}

When asked about familiarity with biological medicines, $58 \%$ of prescribers said they are 'Very familiar', and have a complete understanding of them, compared to $41 \%$ who said the same about biosimilars. Thirty-seven per cent of prescribers said they are "Familiar", with a basic understanding of biologicals, compared to $49 \%$ who said the same about biosimilars. And $4 \%$ had heard of biologicals but could not define them, compared to $8 \%$ who said the same about biosimilars. All prescribers had heard of biologicals whereas $2 \%$ of prescribers have not heard of biosimilars.

\section{Figure 1: Sources to learn details of a medicine for prescribing and monitoring}

Q7. How often do you use each of the following sources to learn about the details of a medicine for prescribing and monitoring? $(n=579)$
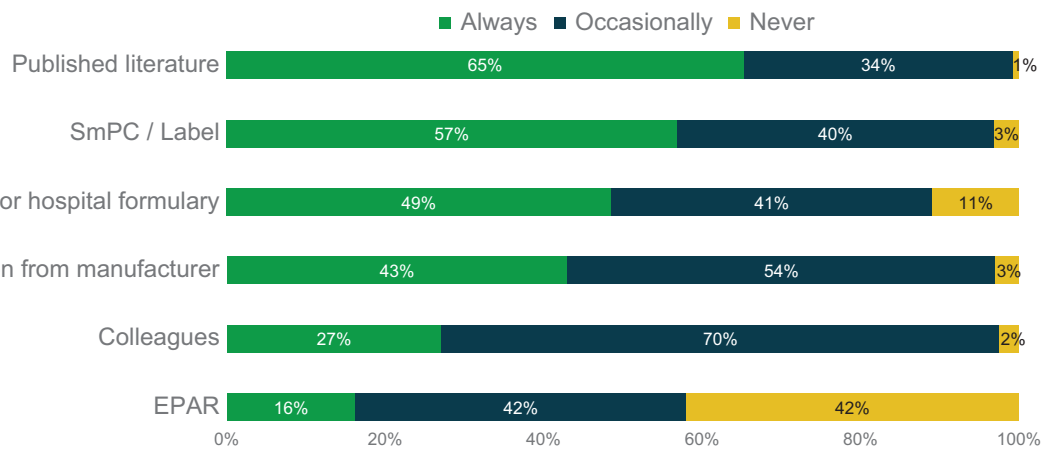

EPAR: European Public Assessment Report; SmPC: summary product characteristics.
Since the 2013 European prescribers study, familiarity with biosimilar medicines increased from $76 \%$ to $90 \%$; and a prescriber's awareness that a biosimilar may be approved for several or all indications of the reference product on the basis of clinical trials in only one of those indications increased from 63\% (2013) to $83 \%$ (2019.) Strongest familiarity with biosimilars was among prescribers in Italy, Spain and Germany (48\%, 47\% and 44\% are very familiar/have complete understanding). Prescribers in Switzerland had the lowest familiarity with only 31\% stating they are very familiar/have complete understanding of biosimilars; 19\% of Swiss prescribers either could not define biosimilars or have never heard of biosimilars.

Strongest familiarity with biological medicines was among Rheumatology and Gastrointestinal prescribers (96\% and 88\% are very familiar/have complete understanding) when compared to the other practice areas. Strongest familiarity of biosimilars was also among Rheumatology, Gastrointestinal and Endocrinology prescribers $(70 \%, 61 \%$ and $60 \%$ are very familiar/have complete understanding).

\section{Preferred route to familiarity}

Of the respondents $(n=517)$ that said they were very familiar/familiar with biosimilar medicines. The top five sources of information were: 1) scientific publications (70\%); 2) national medical conferences/symposia (70\%); 3) international medical conferences/symposia (61\%); 4) self-study (42\%); and 5) CME/ IME $(40 \%)$

The sources varied among the countries. For example, prescribers in the UK became more familiar with biosimilars through self-study (66\%) and scientific publications (56\%), while in Spain scientific publications (73\%) and CME/IME (66\%) were the most utilized.

The top five sources to learn about biosimilars among the respondents $(n=62)$ who had never heard of, nor could define biosimilar medicines were: 1) scientific publications (68\%); 2) international medical conferences/symposia (61\%); 3) national medical conferences/symposia (55\%); 4) CME/IME (37\%); and 5) reference product company sponsored education (35\%).

There were no significant differences in the preferred method for becoming familiar with biosimilars among practitioners in different countries.

\section{Biosimilar approval awareness}

Prescribers in Italy (94\%) had significantly higher biosimilar approval awareness compared to the rest of the countries. The specialties with the highest biosimilar approval awareness were Rheumatology (96\%), Endocrinology (95\%), Oncology (94\%) and Gastrointestinal (92\%) prescribers. All had significantly higher awareness than other specialties. 


\section{Adverse drug reaction reporting: mechanism, recording, information required, barriers}

The survey showed that four out of five prescribers are legally required to report adverse drug reactions (ADRs) that are brought to their attention.

Italian prescribers rated the highest percentage for being required to report ADRs (96\%), and French prescribers the lowest (69\%). The practice areas in which the highest number of prescribers are required to report ADRs were Oncology (91\%) and Immunology (90\%).

More than half (54\%) of prescribers said they are most likely to report an ADR to the National Competent Authority (NCA). The UK is significantly more likely to report to a combination of the NCA, the Marketing Authorization Holder (MAH), i.e. the manufacturer, and EMA (54\%) as opposed to the NCA alone (29\%).

\section{ADR report mechanisms, time spent and follow-up}

Email was utilized by almost half $(49 \%)$ of prescribers $(n=550)$ to report ADRs to the NCA or MAH. However, when looking at specific countries, prescribers in Germany (58\%) and the UK $(52 \%)$ had a majority preference for paper. Prescribers in France (57\%) and Italy (60\%) had a preference for email, while Spain (53\%) preferred a web-based tool/app.

Two-thirds (65\%) of prescriber respondents said that the amount of time spent on filing a report ranged from 10 to 20 minutes, with 25\% requiring less than 10 minutes and 10\% requiring more than 20 minutes (average 36 minutes) While prescribers do file detailed reports, the time varies among the specialtiesDermatology (38\%) prescribers need less time to file compared to other practice areas, whilst Neurology (19\%), Immunology (17\%) and Nephrology (14\%) prescribers need more than 20 minutes to file the ADR report.

In terms of follow up from the NCA or MAH, $24 \%$ of prescribers responded they always receive follow-up, 21\% very often, 30\% sometimes, 19\% rarely and 6\% never. Prescribers in Switzerland have one of the highest rates of follow up from reporting entities (Always, 35\%) compared to several other countries.

\section{Information included in the ADR reports}

When ADR reports are filed for a biological medication, 92\% of practitioners responded that information about the ADR experienced by the patient are included, $84 \%$ include brand name of the biological suspected to have caused the incident, $80 \%$ include date and time of report, $72 \%$ include the nonproprietary name of the biological suspected to have caused the incident, 69\% include batch number of the biological suspected to have caused the incident, including the manufacturer of the product suspected to have been associated with the reaction.

Prescribers in Italy (79\%) are better about including batch number in the ADR report; Germany (74\%) prescribers are better about including the manufacturer of the product; prescribers in the UK (90\%) are better about including date and time.
When asked about how frequently the NCA or MAH follow-up to request the brand name or manufacturer of the product, $55 \%$ of prescribers responded either always or very often, $28 \%$ said sometimes, while 18\% said rarely or never.

Fifty-five per cent of practitioners said that the level of detail required in ADR reports deters them from reporting minor events. When looking at the country specific data, prescribers in France are significantly more deterred from reporting minor events, while those in Italy are significantly less deterred.

\section{Barriers to reporting ADRs}

Fifty-five per cent of the prescribers responded that the amount of information necessary to report an adverse drug reaction deters them from reporting minor events. France $(74 \%)$ is significantly more deterred from reporting minor events, while Italy (38\%) is significantly less deterred.

More than half $(56 \%)$ of prescribers responded that reporting infrastructure, e.g. the mechanism of reporting ADRs, was the biggest barrier to accurate reporting; another 20\% responded no barriers exist. When looking at the country specific data, prescribers in Spain identified reporting infrastructure (70\%) and lack of integration of electronic health records (55\%) as barriers to accurate reporting more so than most countries.

Nearly all prescribers responded that they were somewhat confident (62\%) or highly confident (36\%) in the European pharmacovigilance system's ability to accurately identify the specific product at the brand-name level that might be responsible for the ADR. However, prescribers in the UK were less confident in the European pharmacovigilance system than the other countries surveyed, with only $24 \%$ reporting they were 'highly confident' the system would be able to accurately identify the product responsible.

Frequency of including batch number when reporting adverse events was mixed; $37 \%$ always, $27 \%$ very often, $20 \%$ sometimes, $17 \%$ rarely/never. The survey showed that prescribers in Italy (55\%) were best about including batch number (always) when compared to most of other countries. Of the prescribers who said they only included batch number sometimes, rarely, or never, more than half $(53 \%)$ of prescribers responded that the reason for this was due to not having it available at time of reporting.

\section{Automatic substitution, switching and physician choice}

A high majority of prescribers (82\%) feel very strongly about having control over what is prescribed and dispensed to their patients.

\section{Opinion on sole authority for prescribers}

Most prescribers agreed that it is either critical or very important $(82 \%)$ that they had the sole authority, together with their patients, to decide on the most suitable biological medicine for their disease. When looking at each country, it is significantly more critical to have sole authority in deciding medicine for prescribers in Italy (94\%), Switzerland (91\%) and Germany (84\%). When looking at specific fields, it was most important/ critical to have sole authority in deciding biological medicine for Immunology (86\%), Dermatology (86\%) and Ophthalmology 
(86\%) prescribers. It was least important/critical for Haematology-Oncology prescribers, $20 \%$ of whom considered it slightly/ not important, compared to an average of $2 \%$ across all specialties which thought this, see Figure 2 .

\section{Figure 2: Sole authority to decide on suitable biological medicine for disease (practice area)}

Q25. How important is it to you to have the sole authority to decide, together with your patients, the most suitable biological medicine for their disease? $(n=579)$
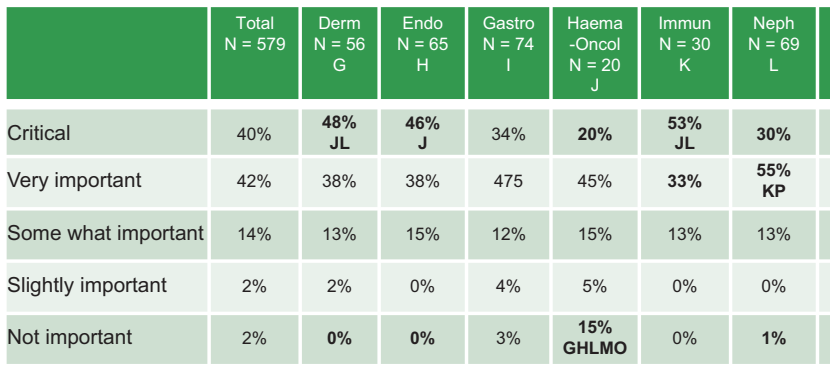

\begin{tabular}{|c|c|c|c|}
\hline $\begin{array}{c}\text { Neur } \\
N=81 \\
M\end{array}$ & $\begin{array}{c}\text { Oncol } \\
\mathrm{N}=34 \\
\mathrm{~N}\end{array}$ & $\begin{array}{c}\text { Ophth } \\
N=70 \\
0\end{array}$ & $\begin{array}{c}\text { Rheum } \\
\mathrm{N}=80 \\
\mathrm{P}\end{array}$ \\
\hline $35 \%$ & $41 \%$ & $40 \%$ & $\begin{array}{c}49 \% \\
\mathrm{JL}\end{array}$ \\
\hline $41 \%$ & $41 \%$ & $46 \%$ & $36 \%$ \\
\hline$\underset{P}{21 \%}$ & $15 \%$ & $13 \%$ & $9 \%$ \\
\hline $4 \%$ & $0 \%$ & $1 \%$ & $4 \%$ \\
\hline $0 \%$ & $3 \%$ & $0 \%$ & $3 \%$ \\
\hline
\end{tabular}

It is significantly more critical to have sole authority in deciding medicine for Immunology, Rheumatology, Dermatology, and Endocrinology.

Figure 3: Authority to deny substitution (practice area)

Q28. In a situation where substitution by a pharmacist was an option in your country, how important would it be to you to have the authority to designate a biological medicine as "DISPENSE AS WRITTEN" or "DO NOT SUBSTITUTE"? $(n=579)$

\begin{tabular}{|c|c|c|c|c|c|c|c|c|c|c|c|}
\hline & $\begin{array}{c}\text { Total } \\
\mathrm{N}=579\end{array}$ & $\begin{array}{c}\text { Derm } \\
N=56 \\
G\end{array}$ & $\begin{array}{c}\text { Endo } \\
\mathrm{N}=65 \\
\mathrm{H}\end{array}$ & $\begin{array}{c}\text { Gastro } \\
\mathrm{N}=74 \\
\text { I }\end{array}$ & $\begin{array}{c}\text { Haema } \\
- \text { Oncol } \\
\mathrm{N}=20 \\
\mathrm{~J}\end{array}$ & $\begin{array}{c}\text { Immun } \\
\mathrm{N}=30 \\
\mathrm{~K}\end{array}$ & $\begin{array}{c}\text { Neph } \\
N=69 \\
L\end{array}$ & $\begin{array}{c}\text { Neur } \\
\mathrm{N}=81 \\
\mathrm{M}\end{array}$ & $\begin{array}{c}\text { Oncol } \\
\mathrm{N}=34 \\
\mathrm{~N}\end{array}$ & $\begin{array}{c}\text { Ophth } \\
N=70 \\
0\end{array}$ & $\begin{array}{c}\text { Rheum } \\
\mathrm{N}=80 \\
\mathrm{P}\end{array}$ \\
\hline Critical & $46 \%$ & $50 \%$ & $\begin{array}{c}52 \% \\
\mathrm{~J}\end{array}$ & $47 \%$ & $25 \%$ & $47 \%$ & $48 \%$ & $40 \%$ & $32 \%$ & $47 \%$ & $\begin{array}{l}55 \% \\
\text { JMN }\end{array}$ \\
\hline Very important & $38 \%$ & $38 \%$ & $29 \%$ & $42 \%$ & $35 \%$ & $40 \%$ & $41 \%$ & $43 \%$ & $44 \%$ & $37 \%$ & $35 \%$ \\
\hline Somewhat important & $12 \%$ & $11 \%$ & $\begin{array}{c}17 \% \\
P\end{array}$ & $5 \%$ & $20 \%$ & $10 \%$ & $12 \%$ & $14 \%$ & $18 \%$ & $14 \%$ & $6 \%$ \\
\hline Slightly important & $3 \%$ & $2 \%$ & $2 \%$ & $4 \%$ & $\begin{array}{c}20 \% \\
\text { GHILMNOP }\end{array}$ & $3 \%$ & $0 \%$ & $4 \%$ & $0 \%$ & $1 \%$ & $4 \%$ \\
\hline Not important & $1 \%$ & $0 \%$ & $0 \%$ & $1 \%$ & $0 \%$ & $0 \%$ & $0 \%$ & $0 \%$ & $6 \%$ & $0 \%$ & $0 \%$ \\
\hline
\end{tabular}

It is significantly less important for Haematology oncology to be able to deny substitution than almost all other practice areas.

\section{Figure 4: Identify medicine by brand name (country, practice area)}

Q29. When you prescribe medicine, including biologicals, do you identify the medicine in the patient record by brand name? $(n=579)$
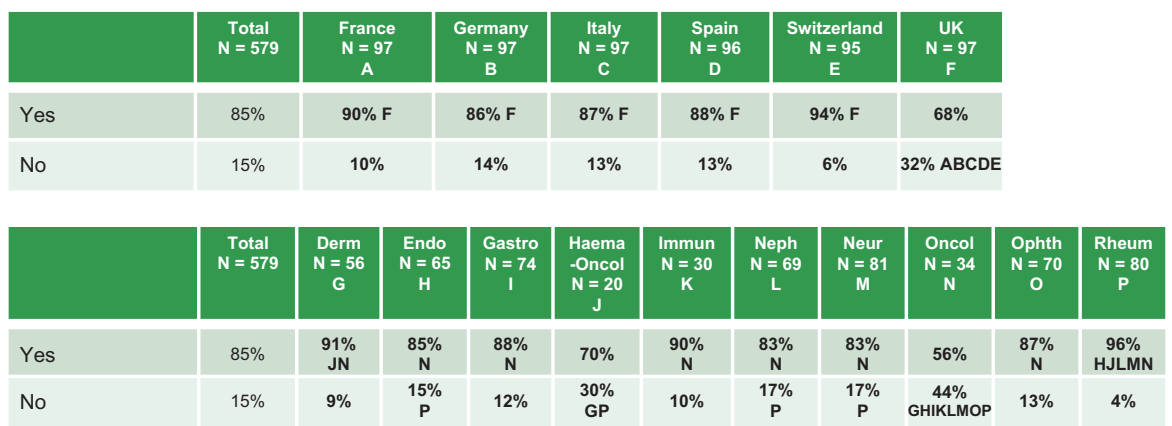

UK and Oncology identify medicine in a patient's record by brand name significantly less than other countries and practice areas.

\section{Government tenders}

Most prescribers stated that they believe it is very important or critical (63\%) that government tenders for biosimilars are awarded to multiple suppliers. Prescribers in Spain and the UK, while considering this very important, do not think it is as critical for government tenders to be awarded when compared to the other countries surveyed. Only $7 \%$ and $9 \%$ considered this 'critical' compared to an 18\% average across all other respondents.

Most prescribers agreed that it is either critical or very important (83\%) that factors besides price to be taken into account in national tender offers, e.g. reliability of supply, patient support services, manufacturer reputation.

\section{Prescriber authority to deny substitution}

Most prescribers agreed that it is either critical or very important (84\%) that, in a situation where substitution by a pharmacist was an option in their country, they have the authority to designate a biological medicine as 'DISPENSE AS WRITTEN' or 'DO NOT SUBSTITUTE'. It was significantly more critical for those in Switzerland (94\%) to have authority to deny substitution for a biological medicine, and least so for those in the UK $(73 \%)$, compared to those in the other countries. It was significantly less important for Haematology-Oncology prescribers to be able to deny substitution when compared to almost all other practice areas, see Figure 3.

\section{Identifying medicines}

Eighty-five per cent of prescribers said that, when prescribing medicine including biologicals, they identify the medicine in the patient record by brand name. When looking at country and practice area responses, UK (68\%) and Oncology (56\%) identify medicine in a patient's record by brand name significantly less than those in other countries and practice areas, see Figure 4.

Forty-three per cent of prescribers 
responded they rarely or never prescribe biological products by non-proprietary name only. When compared to the other countries, prescribers in Switzerland (40\%) are most likely never to use the non-proprietary name of a product. When compared to those in other practice areas, Dermatology (32\%) and Rheumatology (28\%) prescribers are more likely never to use the non-proprietary name of a product, see Figure 5.

When asked about how confident a prescriber can be in their ability to know exactly what product is dispensed to a patient when using a non-proprietary name, 63\% were very or somewhat confident, while 38\% were slightly confident or not confident at all. Prescribers in Switzerland (26\% are not confident at all) noted that they are significantly less confident in knowing what is dispensed when a non-proprietary name is used than those in Italy, Spain and the UK. Prescribers in the fields of Dermatology (55\%) and Rheumatology (42\%) are significantly less confident in knowing what is dispensed when a non-proprietary name is used compared to those in several other practice areas, see Figure 6.

\section{Figure 5: Use of non-proprietary name in practice area}

Q30. How often do you prescribe biological products by non-proprietary name only? $(n=579)$

\begin{tabular}{|c|c|c|c|c|c|c|c|c|c|c|c|}
\hline & $\begin{array}{c}\text { Total } \\
\mathrm{N}=579\end{array}$ & $\begin{array}{c}\text { Derm } \\
N=56 \\
G\end{array}$ & $\begin{array}{c}\text { Endo } \\
\mathrm{N}=65 \\
\mathrm{H}\end{array}$ & $\begin{array}{c}\text { Gastro } \\
\mathrm{N}=74 \\
\mathrm{I}\end{array}$ & $\begin{array}{c}\text { Haema } \\
- \text { Oncol } \\
\mathrm{N}=20 \\
\mathrm{~J}\end{array}$ & $\begin{array}{c}\text { Immun } \\
\mathrm{N}=30 \\
\mathrm{~K}\end{array}$ & $\begin{array}{c}\text { Neph } \\
N=69 \\
L\end{array}$ & $\begin{array}{c}\text { Neur } \\
\mathrm{N}=81 \\
\mathrm{M}\end{array}$ & $\begin{array}{c}\text { Oncol } \\
N=34 \\
N\end{array}$ & $\begin{array}{c}\text { Ophth } \\
N=70 \\
0\end{array}$ & $\begin{array}{c}\text { Rheum } \\
\mathrm{N}=80 \\
\mathrm{P}\end{array}$ \\
\hline Always & $5 \%$ & $4 \%$ & $6 \%$ & $8 \%$ & $0 \%$ & $3 \%$ & $3 \%$ & $1 \%$ & $\begin{array}{l}15 \% \\
\text { LMO }\end{array}$ & $1 \%$ & $8 \%$ \\
\hline Very often & $22 \%$ & $23 \%$ & $17 \%$ & $18 \%$ & $25 \%$ & $23 \%$ & $\begin{array}{c}29 \% \\
P\end{array}$ & $21 \%$ & $\begin{array}{c}44 \% \\
\text { GHIMOP }\end{array}$ & $24 \%$ & $13 \%$ \\
\hline Sometimes & $31 \%$ & $21 \%$ & $28 \%$ & $30 \%$ & $35 \%$ & $40 \%$ & $29 \%$ & $\begin{array}{l}38 \% \\
\text { GP }\end{array}$ & $29 \%$ & $\begin{array}{l}40 \% \\
\text { GP }\end{array}$ & $23 \%$ \\
\hline Rarely & $26 \%$ & $20 \%$ & $\begin{array}{c}37 \% \\
\text { GN }\end{array}$ & $\begin{array}{c}27 \% \\
N\end{array}$ & $25 \%$ & $20 \%$ & $23 \%$ & $25 \%$ & $9 \%$ & $\begin{array}{c}27 \% \\
N\end{array}$ & $\begin{array}{c}30 \% \\
\mathrm{~N}\end{array}$ \\
\hline Never & $17 \%$ & $32 \%$ & $\begin{array}{c}32 \% \\
\text { HLMNO }\end{array}$ & $18 \%$ & $15 \%$ & $13 \%$ & $16 \%$ & $15 \%$ & $3 \%$ & $7 \%$ & $\begin{array}{c}28 \% \\
\text { HMNO }\end{array}$ \\
\hline
\end{tabular}

Compared to other practice areas, Dermatology and Rheumatology never use the non-proprietary name of a product more so.

Figure 6: Confidence in what is dispensed using non-proprietary name (practice area)

Q31. If you prescribed a product using the non-proprietary name, how confident are you in your ability to know exactly what product will be dispensed to the patient? $(n=579)$

\begin{tabular}{|c|c|c|c|c|c|c|c|c|c|c|c|}
\hline & $\begin{array}{l}\text { Total } \\
\mathrm{N}=579\end{array}$ & $\begin{array}{c}\text { Derm } \\
N=56 \\
G\end{array}$ & $\begin{array}{c}\text { Endo } \\
\mathrm{N}=65 \\
\mathrm{H}\end{array}$ & $\begin{array}{c}\text { Gastro } \\
\mathrm{N}=74 \\
\mathrm{I}\end{array}$ & $\begin{array}{c}\text { Haema } \\
- \text { Oncol } \\
\mathrm{N}=20 \\
\mathrm{~J}\end{array}$ & $\begin{array}{c}\text { Immun } \\
\mathrm{N}=30 \\
\mathrm{~K}\end{array}$ & $\begin{array}{c}\text { Neph } \\
N=69 \\
L\end{array}$ & $\begin{array}{c}\text { Neur } \\
\mathrm{N}=81 \\
\mathrm{M}\end{array}$ & $\begin{array}{c}\text { Oncol } \\
\mathrm{N}=34 \\
\mathrm{~N}\end{array}$ & $\begin{array}{c}\text { Ophth } \\
N=70 \\
0\end{array}$ & $\begin{array}{c}\text { Rheum } \\
\mathrm{N}=80 \\
\mathrm{P}\end{array}$ \\
\hline Very confident & $15 \%$ & $9 \%$ & $18 \%$ & $12 \%$ & $20 \%$ & $20 \%$ & $14 \%$ & $10 \%$ & $21 \%$ & $13 \%$ & $18 \%$ \\
\hline Somewhat confident & $48 \%$ & $36 \%$ & $45 \%$ & $43 \%$ & $40 \%$ & $\begin{array}{l}63 \% \\
\text { GP }\end{array}$ & $52 \%$ & $44 \%$ & $\begin{array}{c}59 \% \\
G\end{array}$ & $\begin{array}{l}61 \% \\
\text { GIMP }\end{array}$ & $41 \%$ \\
\hline Slightly confident & $24 \%$ & $\begin{array}{c}32 \% \\
0\end{array}$ & $22 \%$ & $27 \%$ & $30 \%$ & $13 \%$ & $23 \%$ & $\begin{array}{l}35 \% \\
\text { KNOP }\end{array}$ & $15 \%$ & $16 \%$ & $19 \%$ \\
\hline Not confident at all & $14 \%$ & $\begin{array}{c}23 \% \\
\text { KLNO }\end{array}$ & $15 \%$ & $18 \%$ & $10 \%$ & $3 \%$ & $10 \%$ & $11 \%$ & $6 \%$ & $10 \%$ & $\begin{array}{c}23 \% \\
\text { KLNO }\end{array}$ \\
\hline
\end{tabular}

Dermatology and Rheumatology are significantly less confident in knowing what is dispensed when a nonproprietary name is used than several other practice areas.

\section{Figure 7: Confidence in what is dispensed (biological product) by pharmacy (practice area)}

Q32. This question pertains only to biological products dispensed directly to a patient from a pharmacy. If the pharmacy dispenses a drug that is different from the one that is prescribed (whether it is biosimilar 1, 2 or 3 or even the reference product), how confident are you inyour ability to identify exactly what drug was dispensed to the patient? $(n=579)$

\begin{tabular}{|c|c|c|c|c|c|c|c|c|c|c|c|}
\hline & $\begin{array}{c}\text { Total } \\
\mathrm{N}=579\end{array}$ & $\begin{array}{c}\text { Derm } \\
N=56 \\
G\end{array}$ & $\begin{array}{c}\text { Endo } \\
\mathrm{N}=65 \\
\mathrm{H}\end{array}$ & $\begin{array}{c}\text { Gastro } \\
N=74 \\
I\end{array}$ & $\begin{array}{c}\text { Haema } \\
- \text { Oncol } \\
\mathrm{N}=20 \\
\mathrm{~J}\end{array}$ & $\begin{array}{c}\text { Immun } \\
\mathrm{N}=30 \\
\mathrm{~K}\end{array}$ & $\begin{array}{c}\text { Neph } \\
N=69 \\
L\end{array}$ & $\begin{array}{c}\text { Neur } \\
\mathrm{N}=81 \\
\mathrm{M}\end{array}$ & $\begin{array}{c}\text { Oncol } \\
N=34 \\
N\end{array}$ & $\begin{array}{c}\text { Ophth } \\
\mathrm{N}=70 \\
0\end{array}$ & $\begin{array}{c}\text { Rheum } \\
\mathrm{N}=80 \\
\mathrm{P}\end{array}$ \\
\hline Very confident & $13 \%$ & $5 \%$ & $12 \%$ & $11 \%$ & $20 \%$ & $13 \%$ & $7 \%$ & $11 \%$ & $\begin{array}{c}38 \% \\
\text { GHIKLMOP }\end{array}$ & $11 \%$ & $\begin{array}{c}20 \% \\
\mathrm{GL}\end{array}$ \\
\hline Somewhat confident & $48 \%$ & $41 \%$ & $49 \%$ & $53 \%$ & $40 \%$ & $60 \%$ & $58 \%$ & $42 \%$ & $44 \%$ & $44 \%$ & $46 \%$ \\
\hline Slightly confident & $26 \%$ & $\begin{array}{c}32 \% \\
\mathrm{~N}\end{array}$ & $25 \%$ & $24 \%$ & $30 \%$ & $27 \%$ & $25 \%$ & $\begin{array}{c}27 \% \\
N\end{array}$ & $9 \%$ & $\underset{N}{31 \%}$ & $25 \%$ \\
\hline Not confident at all & $13 \%$ & $\begin{array}{l}21 \% \\
\text { KP }\end{array}$ & $14 \%$ & $12 \%$ & $10 \%$ & $0 \%$ & $10 \%$ & $\begin{array}{l}20 \% \\
\mathrm{KP}\end{array}$ & $9 \%$ & $13 \%$ & $9 \%$ \\
\hline
\end{tabular}

\section{Dispensing in pharmacies}

When asked about biological products dispensed directly to patients in a pharmacy, $61 \%$ of prescribers said that they were either very confident or somewhat confident that, if the pharmacy dispenses a drug that is different from the one that is prescribed (whether it is biosimilar 1,2 , or 3 or even the reference product), they have the ability to identify exactly what drug was dispensed to the patient. Thirty-nine per cent were either slightly confident or not confident at all. Prescribers in the UK (73\%) said they are significantly more confident in knowing what is dispensed by pharmacy than those in Germany (49\%) and Spain (60\%); and those in Switzerland (24\% not confident at all) are significantly less confident than several countries. It was shown that Oncology (82\%) prescribers are significantly more confident in knowing what is dispensed than those in almost all of the other practice areas, see Figure 7.

Eighty-three per cent of prescribers said it was critical or very important to be notified by the pharmacist if a patient has received a biological other than the one prescribed, if the patient was receiving chronic (repeated) treatment. It was shown to be significantly more critical for prescribers in Switzerland $(80 \%)$ to be notified that a different biological was prescribed than for those in all other surveyed countries. It was also shown that it is significantly more critical for Rheumatology (84\%) prescribers to be notified that a different biological was prescribed than those in several other practice areas; and it is significantly less important for Haematology-Oncology prescribers to be notified.

Only 5\% of prescribers thought it was totally acceptable for a pharmacist to determine which biological (reference 


\section{Figure 8: Can pharmacist make decision (practice area)}

Q34. How acceptable would it be for you if the pharmacist made the determination which biologic (reference product or biosimilar) to dispense to your] patient on initiation of treatment? $(n=579)$

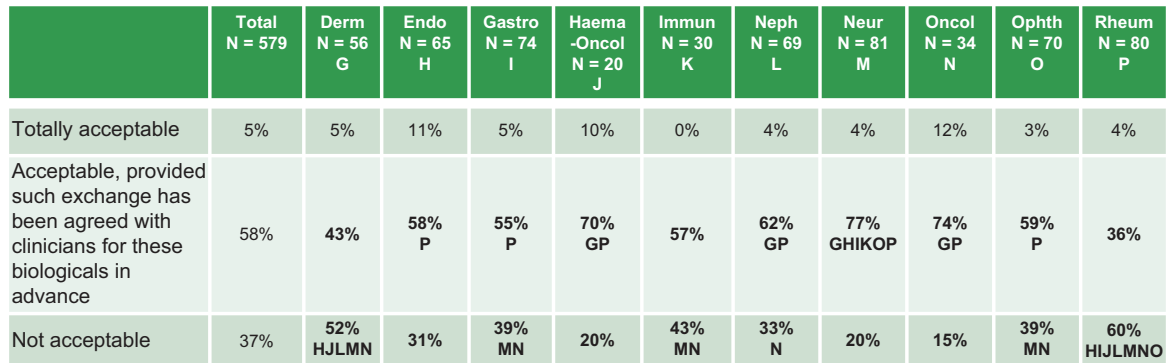

It is significantly not acceptable for a pharmacist to make decision more so for Rheumatology and Dermatology compared to other practice areas.

\section{Figure 9: Prescribe biosimilar to naïve patient (practice area)}

Q36. How comfortable are you in prescribing a biosimilar to a treatment 'naïve' patient? $(n=579)$
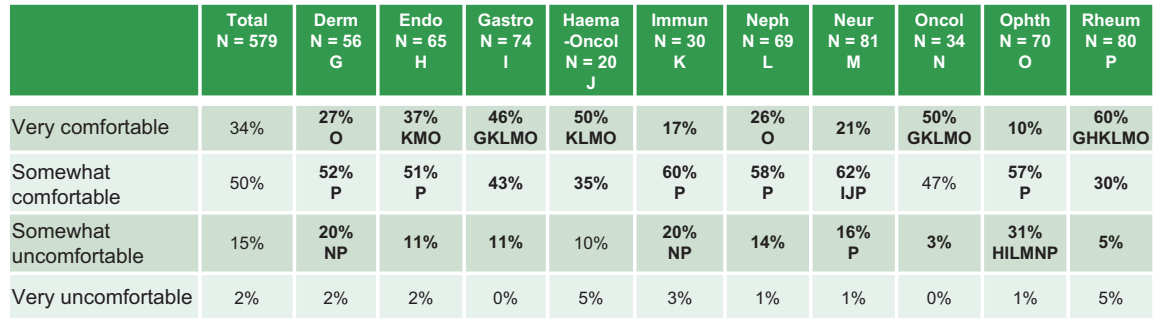

Rheumatology is more comfortable (very) than many other practice areas in prescribing a biosimilar to a naïve patient; Ophthalmology is least comfortable.

\section{Figure 10: Switch patient to biosimilar (practice area)}

Q37. How comfortable are you with switching a stable patient from one medicine to a biosimilar? $(n=579)$
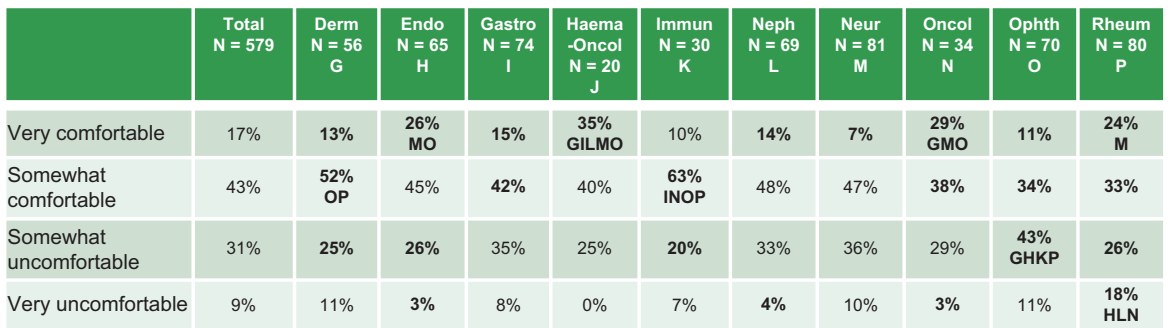

Haematology-Oncology and Oncology are more comfortable (very) switching a stable patient to a biosimila than several other practice areas; Ophthalmology and Rheumatology are less comfortable.

\section{Prescribing biosimilars and switching}

Seventy-four per cent of prescribers agreed that the correct definition for a 'naïve' patient is: a patient that has never received any biological treatment from this class of medicines. Eightyfour per cent of prescribers said they were very comfortable or somewhat comfortable in prescribing biosimilars to treat naïve patients. Prescribers in France, Germany, Italy, Switzerland and the UK are significantly more comfortable (very) than those in Spain (18\%) in prescribing a biosimilar to a naïve patient. Rheumatology (60\%) prescribers are more comfortable (very) than those of many other practice areas in prescribing a biosimilar to a naïve patient; Ophthalmology (10\%) prescribers are the least comfortable.

Comfort level decreases when asked about switching a stable patient to a biosimilar versus to a naïve patient. While $17 \%$ are uncomfortable in prescribing a biosimilar to a naïve patient, see Figure 9; twice as many (40\%) are uncomfortable with switching a stable patient from an originator to a biosimilar. Spain (54\%) prescribers are the least comfortable with switching a stable patient to a biosimilar. Haematology-Oncology prescribers are more comfortable switching a stable patient from an originator to a biosimilar than those in several other practice areas; Ophthalmology and Rheumatology prescribers are less comfortable, see Figure 10.

Comfort level decreases further when asked about switching a patient to a biosimilar for non-medical reasons. More than half of prescribers (58\%) said they are uncomfortable with switching their patients to a biosimilar for nonmedical reasons. Prescribers in France are significantly more comfortable

product or biosimilar) to dispense to a patient at the initiation of treatment. Fifty-eight per cent thought this was acceptable if the pharmacist's ability to determine the product was agreed to by clinicians in advance, and $37 \%$ thought it not acceptable. It was shown to be significantly not acceptable for a pharmacist to make the decision for prescribers in Spain (52\%) and Switzerland (51\%) when compared to the other countries surveyed. It was shown to be significantly not acceptable for a pharmacist to make decision more so for Rheumatology (60\%) and Dermatology (52\%) prescribers compared to those in other practice areas, see Figure 8. (very) switching a patient to a biosimilar for non-medical reasons than several other countries; prescribers in Italy and Spain are the least comfortable. Haematology-Oncology prescribers are significantly more comfortable (very) switching a patient to a biosimilar for non-medical reasons than those in most other practice areas, see Figure 11.

Even more prescribers are uncomfortable (73\%) when asked about a third party initiating such a switch. In the UK and France, prescribers were shown to be most comfortable with switching their patients ( $40 \%$ and $35 \%$ comfortable, respectively), while 


\section{Figure 11: Switch to biosimilar for non-medical reasons (practice area)}

Q38. How comfortable are you with switching your patient to a biosimilar for non-medical reasons, i.e. coverage? $(n=579)$

\begin{tabular}{|c|c|c|c|c|c|c|c|c|c|c|c|}
\hline & $\begin{array}{l}\text { Total } \\
\mathrm{N}=579\end{array}$ & $\begin{array}{c}\text { Derm } \\
N=56 \\
G\end{array}$ & $\begin{array}{c}\text { Endo } \\
\mathrm{N}=65 \\
\mathrm{H}\end{array}$ & $\begin{array}{c}\text { Gastro } \\
N=74 \\
I\end{array}$ & $\begin{array}{c}\text { Haema } \\
- \text { Oncol } \\
\mathrm{N}=20 \\
\mathrm{~J}\end{array}$ & $\begin{array}{c}\text { Immun } \\
\mathrm{N}=30 \\
\mathrm{~K}\end{array}$ & $\begin{array}{c}\text { Neph } \\
\mathrm{N}=69 \\
\mathrm{~L}\end{array}$ & $\begin{array}{c}\text { Neur } \\
\mathrm{N}=81 \\
\mathrm{M}\end{array}$ & $\begin{array}{c}\text { Oncol } \\
N=34 \\
N\end{array}$ & $\begin{array}{c}\text { Ophth } \\
N=70 \\
0\end{array}$ & $\begin{array}{c}\text { Rheum } \\
\mathrm{N}=80 \\
\mathrm{P}\end{array}$ \\
\hline Very comfortable & $12 \%$ & $9 \%$ & $\begin{array}{c}15 \% \\
M\end{array}$ & $9 \%$ & $\begin{array}{c}45 \% \\
\text { GHIKLMOP }\end{array}$ & $7 \%$ & $9 \%$ & $4 \%$ & $\underset{M}{21 \%}$ & $9 \%$ & $\begin{array}{l}18 \% \\
M\end{array}$ \\
\hline $\begin{array}{l}\text { Somewhat } \\
\text { comfortable }\end{array}$ & $30 \%$ & $27 \%$ & $32 \%$ & $34 \%$ & $30 \%$ & $33 \%$ & $32 \%$ & $36 \%$ & $24 \%$ & $26 \%$ & $21 \%$ \\
\hline $\begin{array}{l}\text { Somewhat } \\
\text { uncomfortable }\end{array}$ & $38 \%$ & $\begin{array}{l}48 \% \\
\text { IJ }\end{array}$ & $37 \%$ & $30 \%$ & $15 \%$ & $40 \%$ & $\stackrel{42 \%}{J}$ & $\begin{array}{l}41 \% \\
J\end{array}$ & $\stackrel{44 \%}{J}$ & $\begin{array}{l}43 \% \\
J\end{array}$ & $33 \%$ \\
\hline Very uncomfortable & $20 \%$ & $16 \%$ & $15 \%$ & $27 \%$ & $10 \%$ & $20 \%$ & $17 \%$ & $20 \%$ & $12 \%$ & $23 \%$ & $29 \%$ \\
\hline
\end{tabular}

Haematology-Oncology is significantly more comfortable (very) switching a patient to a biosimilar for nonmedical reasons than most other practice areas.

Figure 12: Third-party switch to biosimilar for non-medical reasons

Q39. How comfortable are you with a third party switching your patient to a biosimilar for non-medical reasons, i.e. coverage? $(n=579)$

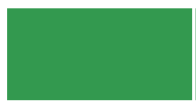

Very comfortable

Somewhat comfortable

Somewhat uncomfortable

Very uncomfortable
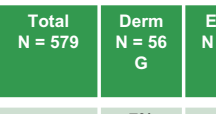

$7 \%$

$20 \%$

$36 \%$

$37 \%$
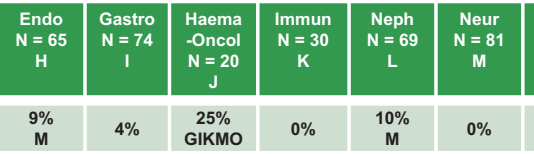

$\stackrel{10 \%}{M}$ $\stackrel{27 \%}{P}$ \begin{tabular}{|l|l|}
\hline $23 \%$ & $35 \%$ \\
\hline
\end{tabular}

\begin{tabular}{|c|c|c|}
\hline $\mathbf{3 8} \%$ & $25 \%$ & $\begin{array}{c}\mathbf{5 0} \% \\
\mathbf{N P}\end{array}$ \\
\hline $35 \%$ & $15 \%$ & $\mathbf{2 3} \%$ \\
\hline
\end{tabular}

$13 \%$

$36 \%$

Haematology-Oncology is significantly more comfortable (very) with a third party switching a patient to a biosimilar for non-medical reasons than several other practice areas.

in Spain, prescribers are the least comfortable with having a third party make the switch (14\%). Haematology-Oncology pre- scribers were shown to be significantly more comfortable with a third party switching a patient to a biosimilar for non-medical reasons (60\% versus an average of $27 \%$ ) than those in several other practice areas, see Figure 12.

\section{Conclusion}

In summary, the survey reveals that European physicians have increased their familiarity with biosimilars since last surveyed in 2013. After 13 years of experience with biosimilars in Europe, physicians:

- Increasingly consider maintaining physician control of treatment decisions to be highly important

- Are more than twice as uncomfortable switching a stable patient to a biosimilar than they are prescribing a biosimilar to a treatment-naïve patient

- Remain uncomfortable with switching a patient to a biosimilar for nonmedical reasons

- Are highly uncomfortable with a non-medical substitution performed by a third party. This figure has increased sharply since the 2013 survey

- Consider it highly important for governments to make multiple thera peutic choices available in tenders; and believe these tenders should take into account factors besides price.

\section{Key points of the 2019 European prescribers survey on biosimilar}

More than half of prescribers are most likely to report an ADR to the National Competent Authority

- Two-thirds of prescribers said amount of time spent on filing a report is 10 to 20 minutes

- Prescribers do file detailed reports; this level of detail in turn deters $55 \%$ from reporting minor events

- More than half of prescribers said reporting infrastructure was the biggest barrier to accurate reporting; another 20\% said no barriers exist

- Frequency of including batch number is mixed; not having the number available at time of reporting was selected by more than half of prescribers who said sometimes, rarely, or never

- Control over prescribing and dispensing - four out of five prescribers feel very strongly about having control over what is prescribed AND dispensed to their patients. Italy prescribers expressed the highest importance in having sole authority to decide the medicine, while France prescribers expressed the least. Switzerland prescribers expressed the highest importance in having the ability to deny a pharmacist's substitution, while UK prescribers expressed the least. Having this level of control was most important to Immunology, Rheumatology, Endocrinology and Dermatology prescribers.

- Product Name and Pharmacist Control

- More than $40 \%$ of prescribers said they rarely or never prescribe biological products by non-proprietary name only

- More than one-third said confidence would be lacking in knowing exactly what was dispensed to patient if they prescribed a product using non-proprietary name

- Four out of five prescribers said it would be critical or very important to be notified by pharmacist that patient received a biological medication other than one they prescribed

- Fifty-eight per cent of prescribers said it would be acceptable for a pharmacist to determine which biological to dispense on initiation of treatment, but would require clinician agreement in advance

- Prescribe Biosimilar versus Switch to Biosimilar - comfort level decreases when asked about switching a stable patient to a biosimilar versus prescribing a biosimilar to a 
naïve patient. About $20 \%$ are uncomfortable in prescribing a biosimilar to a naïve patient; twice as many (40\%) are uncomfortable with switching a stable patient from an originator to a biosimilar. France, Switzerland and UK prescribers are most comfortable with prescribing a biosimilar to a naïve patient, while Spain prescribers are the least comfortable with switching a stable patient to a biosimilar.

- Prescriber Switch versus Third-Party Switch - Comfort level decreases when asked about switching a patient to a biosimilar for non-medical reasons. More than half of prescribers (58\%) are uncomfortable with switching their patients to a biosimilar for non-medical reasons; this percentage increases to $73 \%$ when asked about a third party initiating such a switch. UK and France prescribers are most comfortable with switching their patients, while Spain prescribers are the least comfortable with having a third party make the switch.

\section{Funding sources}

The survey study was sponsored by Alliance for Safe Biologic Medicines (ASBM) and administered by Industry Standard Research, LLC.

This paper is funded by the ASBM.

The ASBM is an organization composed of diverse healthcare groups and individuals - from patients to physicians, innovative medical biotechnology companies and others - who are working together to ensure patient safety is at the forefront of the biosimilars policy discussion. The activities of ASBM are funded by its member partners who contribute to ASBM's activities. Visit www.SafeBiologics.org for more information.

Competing interests: Dr Madelaine Feldman is the Chairperson of the Alliance for Safe Biologic Medicines. She has participated in advisory boards for Gilead, Lilly, Pfizer and Samsung. Mr Michael S Reilly, Esq, is the Executive Director and employed by Alliance for Safe Biologic Medicines. Mr Reilly served in the US Department of Health and Human Services from 2002-2008.

Provenance and peer review: Not commissioned; externally peer reviewed.

\section{Authors}

Madelaine Feldman, MD, FACR

Michael S Reilly, Esq

Alliance for Safe Biologic Medicines, PO Box 3691, Arlington, VA 22203, USA

\section{References}

1. GaBI Online-Generics and Biosimilars Initiative. EU guidelines for biosimilars. Available from: www.gabionline.net/Guidelines/EU-guidelines-for-biosimilars
2. Bird E. Generics and Biosimilars Initiative Journal (GaBI Journal). 2020;9(1):37 44. doi:10.5639/gabij. 2020.0901.007

3. Schneider PJ, Reilly MS. Policy recommendations for a sustainable biosimilars market: lessons from Europe. Generics and Biosimilars Initiative Journal (GaBI Journal). 2020;9(2):76-83. doi:10.5639/gabij.2020.0902.013

4. Jensen AR. Biosimilar product labels in Europe: what information should they contain? Generics and Biosimilars Initiative Journal (GaBI Journal). 2017;6(1):38-40. doi:10.5639/gabij.2017.0601.008

5. Murby SP, Reilly MS. A survey of Australian prescribers' views on the naming and substitution of biologicals. Generics and Biosimilars Initiative Journal (GaBI Journal). 2017;6(3):107-13.doi:10.5639/gabij.2017.0603.022

6. Dolinar RO, Reilly MS. Biosimilars naming, label transparency and authority of choice - survey findings among European physicians. Generics and Biosimilars Initiative Journal (GaBI Journal). 2014;3(2):58-62. doi:10.5639/ gabij.2014.0302.018

7. Schneider PJ, Reilly MS. Naming and labelling of biologicals - the perspective of hospital and retail pharmacists. Generics and Biosimilars Initiative Journal (GaBI Journal). 2016;5(4):151-5. doi:10.5639/gabij.2016.0504.040

8. Safe Biologics. Members partners [homepage on the Internet]. [cited 2021 Aug 9]. Available from: www.https://safebiologics.org/member-partners/

9. Derbyshire M. USA and Europe differ in interchangeability of biosimilars. Generics and Biosimilars Initiative Journal (GaBI Journal). 2017;6(4):183-4 doi:10.5639/gabij.2017.0604.039

10. Reilly MS, Gewanter HL. Prescribing practices for biosimilars: questionnaire survey findings from physicians in Argentina, Brazil, Colombia and Mexico. Generics and Biosimilars Initiative Journal (GaBI Journal). 2015;4(4):161-6. doi:10.5639/gabij.2015.0404.036

11. Gewanter HL, Reilly MS. Naming and labelling of biologicals - a survey of US physicians' perspectives. Generics and Biosimilars Initiative Journal (GaBI Journal). 2017;6(1):7-12. doi:10.5639/gabij. 2017.0601.003

DOI: $10.5639 /$ gabij.2020.0903.020

Copyright @ 2020 Pro Pharma Communications International

Quality standards for biopharmaceuticals: the importance of good manufacturing practice

References (please see the full manuscript on page 97)

32. Kang HN, Thorpe R, Knezevic I, et al. The regulatory landscape of biosimilars: WHO efforts and progress made from 2009 to 2019. Biologicals. 2020;65:1-9.

33. Watson PD, Thorpe R. First Turkish interactive workshop on regulation and approval of similar biotherapeutic products/biosimilars, 2-3 March 2016, Ankara, Turkey. Generics and Biosimilars Initiative Journal (GaBI Journal). 2016;5(3):134-8. doi:10.5639/

\section{gabij.2016.0503.034}

34. Griffiths E, Ekman N, Thorpe R. First ASEAN educational workshop on regulation and approval of biosimilars/similar biotherapeutic products 2017 - Report. Generics and Biosimilars Initiative Journal (GaBI Journal). 018;7(3):127-32. doi:10.5639/ gabij.2018.0703.025

35. Sia CH, Sia MK, Chan LW. Global challenges in the manufacture, regulation and international harmonization of GMP and quality standards for biopharmaceuticals. Generics and Biosimilars Initiative Journal (GaBI Journal). 2020;9(2):5263. doi:10.5639/gabij.2020.0902.010

36. Abbot S, Agbanyo F, Ahlfors JE, Baghbaderani BA, Bartido S, Bharti K, et al. Report of the international conference on manufacturing and testing of pluripotent stem cells. Biologicals. 2018;56:67-83

DOI: $10.5639 /$ gabij.2020.0903.017

Copyright $\odot 2020$ Pro Pharma Communications International 